\title{
The impact of pharmaceutical policy measures: a structural- break approach
}

\author{
Pedro Pita Barros, Universidade Nova de Lisboa \\ Luis Catela Nunes, Universidade Nova de Lisboa
}

$2009 / 03 / 12$

\begin{abstract}
Pharmaceutical spending in many other countries has had a steep increase in the last decade. The Portuguese Government has adopted several measures to reduce pharmaceutical expenditure growth, ranging from increased co-payments to price decreases determined administratively. Promotion of generic consumption has also ranked high in political priorities.

We assess the overall impact of the several policy measures on total pharmaceutical spending, using monthly data over the period January 1995 - August 2008. Endogenous structural breaks (time-series) methods were employed.

Our findings suggest that policy measures aimed at controlling pharmaceutical expenditure have been, in general, unsuccessful. Two breaks were identified. Both coincide with administratively determined price decreases. Measures aimed at increasing competition in the market had no visible effect on the dynamics of Government spending in pharmaceutical products. In particular, the introduction of reference pricing had only a transitory effect of less than one year, with historical growth resuming quickly.

The consequence of it is a transfer of financial burden from the Government to the patients, with no apparent effect on the dynamics of pharmaceutical spending. This strongly suggests that pharmaceutical companies have been able to adjust to policy measures, in order to sustain their sales. It remains a challenge for the future to identify firms' strategies that supported continued growth of sales, despite the several policy measures adopted.
\end{abstract}

JEL Numbers: I11, I18

Keywords: Pharmaceutical expenditures, structural breaks

Correspondence Address: Pedro P Barros, Faculdade de Economia, Universidade Nova de Lisboa, Campus de Campolide, PT-1099-032 Lisboa, Portugal. Email: Barros: ppbarros@,fe.unl.pt, Nunes: 1cnunes@,fe.unl.pt 


\section{Introduction}

Growth in health expenditures is a concern in many countries. Pharmaceutical spending in several countries has had a steep increase in the last decade. Portugal was no exception to this general trend. The Portuguese Government has adopted a wide range of measures to reduce pharmaceutical expenditure growth, from increased co-payments to price decreases determined administratively. Promotion of generic consumption has also ranked high in political priorities.

The concern with the growth of health expenditures is not specific to Portugal. Policy measures aiming at control of the growth rate of pharmaceutical expenditure can be found in most countries. On the demand side, we can find measures directed to patients' behaviour and measures aimed at the medical profession. Examples of the former are the increasing role of copayments and of education programmes. On measures aimed at the medical profession, we find pharmaceutical budgets, protocols for prescription and promotion of generic drugs. Also on the supply side we can find extensive intervention, such as price controls, profit controls, entry controls (white lists and black lists), regulation of detailing and marketing and promotion of more competition. The Portuguese Government has resorted to most of these measures, making this market a natural ground to look at their impact. To name three recent measures (since 2005) in the Portuguese market, we have the enactment of regulations promoting the use of generic drugs, the introduction of a reference pricing system (which was accompanied by a higher copayment by patients) and global agreement between the Government and the industry to limit the growth of public spending with pharmaceutical products.

We assess what has been the impact of policy measures on the aggregate pharmaceutical consumption in Portugal over time. As the Portuguese National Health Service experimented with many of the policy measures also adopted in other countries, the results are of general interest. We are particularly interested in identifying which, if any, of the measures taken contributed to a change in the growth pattern of pharmaceutical consumption in Portugal.

Mossialos et al (2006) provide an overview of the international experience and document that similar policy measures have been adopted in different countries.. Summarizing their assessment, we may say that most policies have no impact, or at the most only a temporary effect. This is true also of more aggressive measures such as direct price controls. The impact of price controls on drug expenditures has been mitigated by growth in quantities or changes in the mix of products, to include more expensive medicines. The "prescription" from Mossialos et al (2006) is to create the conditions for competition in the generics market and integrate price and reimbursement decisions for on-patent pharmaceutical products. Both have also been attempted in the Portuguese market. The reference pricing mechanism ranks high in this approach, though it is 
not as broad as in Germany (where it brings into the same class patented and off-patent pharmaceutical products).

In the UK, we have observed price cuts and a cap on margins (profits), in an agreement adopted in 2006. Administrative price cuts (across the board) and an agreement to control public expenditure growth were also used in Portugal in the period 2005-2007.

The success of changes in copayments in controlling pharmaceutical expenditures, on the other hand, is far from being assured. Sisto and Zanola (2005) unveil significant effects of copayments in determining slower growth in pharmaceutical expenditures in Italy. This result is further confirmed in Fiorio and Siciliani (2008), who look at the copayment changes on the demand for pharmaceutical prescriptions, taking advantage of regional variation introduced in 2002. They find an economic effect from a co-payment increase (the patient pays more at the moment of consumption) but no effect from a slight copayment decrease. ${ }^{1}$ However, Lee et al. (2006), for Taiwan, have found that generic grouping was far more relevant than copayments.

Our findings, using monthly data from January 1995 to August 2008, suggest that policy measures aimed at controlling pharmaceutical expenditure have been, in general, unsuccessful. The only two significant impacts (October 2005 and February 2007) are associated with administratively determined price decreases across the board. The change is essentially a level change as the underlying trend of the series seems to remain basically the same. Moreover, the impact is larger for Government pharmaceutical expenditure than for total expenditure. The consequence of it is a transfer of financial burden from the Government to the patients, with no apparent effect on the dynamics of pharmaceutical spending. This strongly suggests that pharmaceutical companies have been able to adjust to policy measures, in order to sustain their sales. It remains a challenge for the future to identify firms' strategies that supported continued growth of sales, despite the several policy measures adopted.

The paper is organized in the following way. Section 2 describes the institutional background of the market. Section 3 reports the data and presents a simple trend analysis. Then, Section 4 formally tests for endogenous structural breaks, and discusses the main findings. Finally, Section 5 concludes.

\section{The institutional background}

Consumption of pharmaceutical products has increased in Portugal, like in many other countries. Figure 1 presents the total pharmaceutical consumption relative to GDP for a set of OECD countries. Portugal has the second highest relative effort, just after Greece. Greece is a particular

\footnotetext{
${ }^{1}$ Further description of the Italian situation can be found in Fattore e tal. (2008).
} 
case, due to prevailing low prices. The relative high consumption of pharmaceutical products is, moreover, a lasting phenomenon, being in the top tier of relative spending for more than one decade. $^{2}$

This relative positioning derives more from the low Portuguese GDP, as when measured at per capita values, adjusted for purchasing power parities, Portugal has a relatively low consumption.

Figure 1.

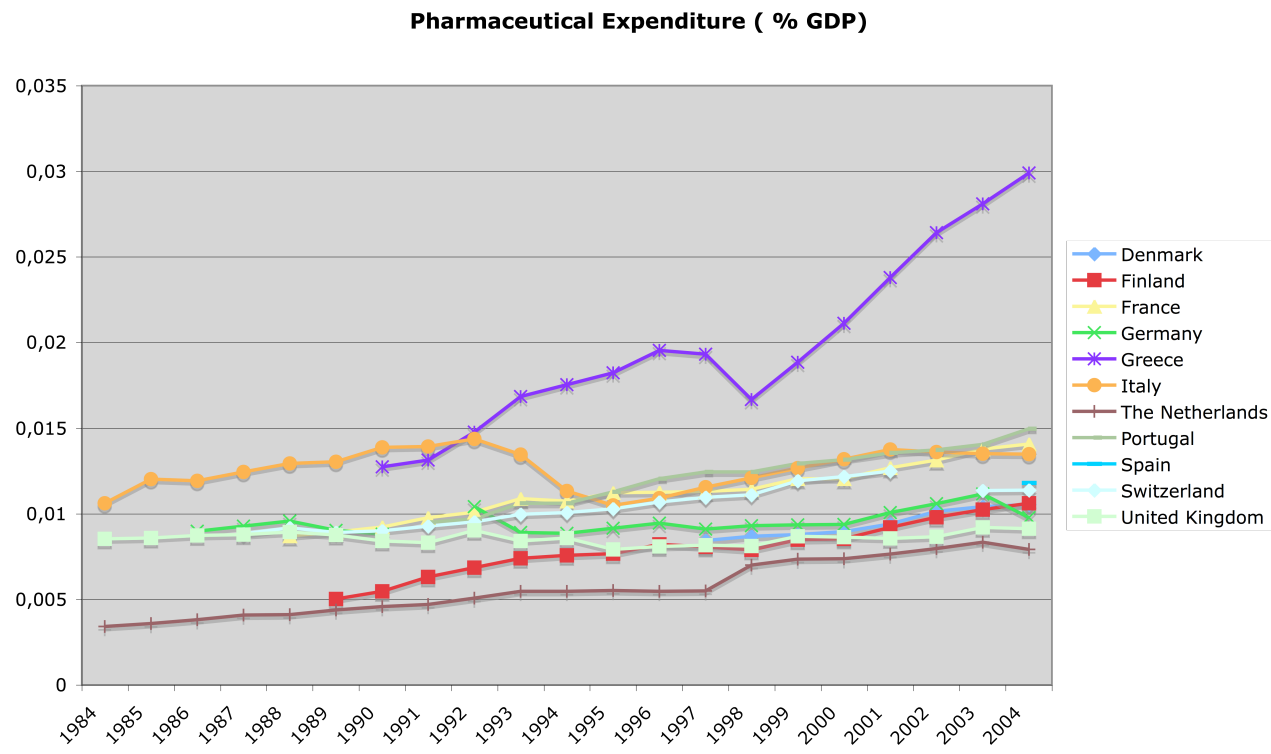

Source: OECD Health Data 2008

\footnotetext{
${ }^{2}$ For a more detailed description of the Portuguese health system, see Barros and Simões (2007).
} 
Figure 2.

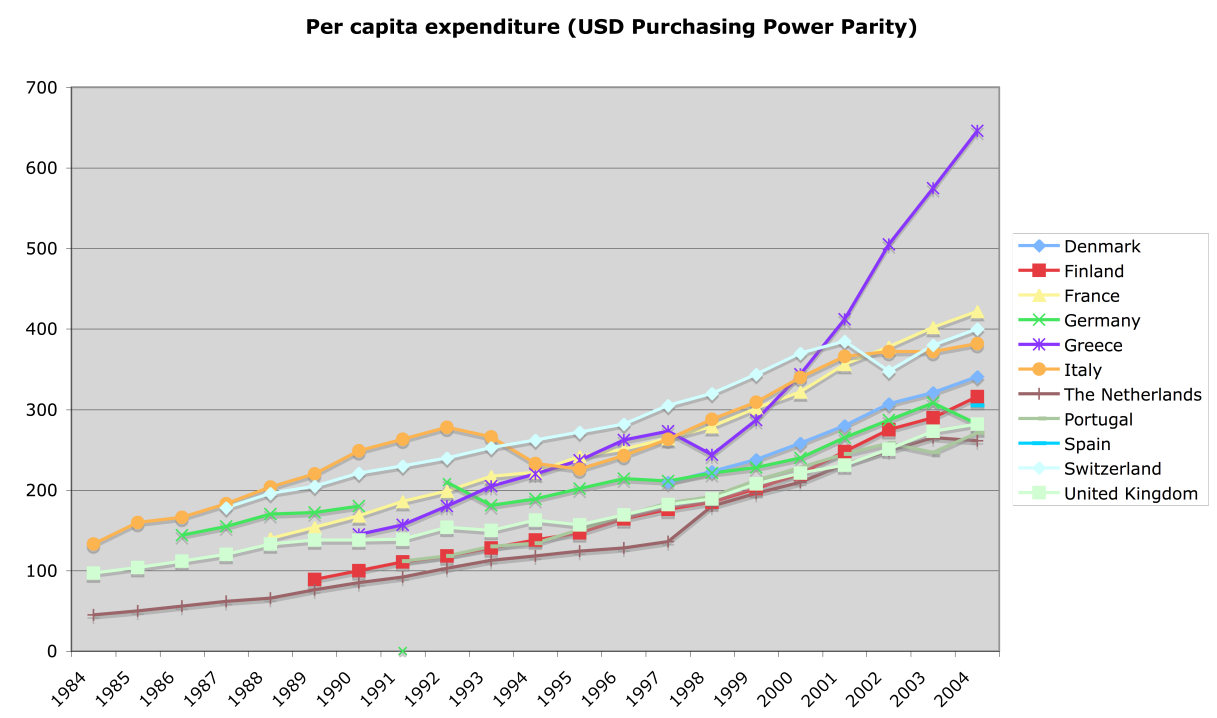

Source: OECD Health Data 2008

This suggests that pressure for increasing value of consumption of pharmaceutical products will exist, which will be demanding due to Portugal's relatively low ability to create wealth. Thus, it comes at no surprise that several measures have been adopted in the past to control growth of pharmaceutical expenditures in the Portuguese market. Policy intervention has occurred at several levels, including price controls, barriers to enter positive lists for reimbursement and other measures aimed at containing pharmaceutical expenditure growth.

Price regulation has been extensive, and follows a complicated procedure. As a first step, after authorization by the pharmaceutical regulatory agency, Infarmed, to introduce the new product into the market, the Ministry of Economy determines a maximum retail price. This maximum price is based on international comparisons, like in other European countries. In particular, currently, it is taken as the average price of the same product in four reference countries (France, Greece, Italy and Spain). ${ }^{3}$ Before 2005, the rule was to take the minimum price of three reference countries (France, Italy and Spain). Given the low prices prevailing in Greece, the change in the computation rule had the expectation of lowering pharmaceutical prices on average.

In the case of introduction of a generic drug, the maximum price is set as $35 \%$ below the corresponding price of the reference branded drug. An exception occurs if the price of the

\footnotetext{
${ }^{3}$ This rule was introduced by Decree-Law 65/2007, of 14th March.
} 
branded drug is below $10 €$ in which case the maximum price for the generic drug will be $20 \%$ below.

After a maximum price set by the Ministry of Economy, the Ministry of Health defines the maximum price for reimbursement purposes, which is necessarily equal or smaller than the maximum price defined by the Ministry of Economy. The reimbursement rate is not set equal to all products. It can take four possible values, according to how essential the product is considered. By September 2007, group A for reimbursement has co-insurance rate of $95 \%$ by the NHS, group B 69\%, group C 37\% and finally group D 15\%. Pensioners with low incomes have additional coinsurance rate by the NHS. Pharmaceutical products also have to face a "fourth hurdle", that is, they have to show a positive cost-benefit analysis (in one of its variants, like cost-effectiveness or cost-utility), according to Guidelines enacted in 1999.

The Government also decides whether, or not, the new product is included in the reference pricing system, created in 2003. In the reference pricing system, the reference price is defined based on the price of the generic product with the highest price within the defined homogeneous group.

Since $2007,{ }^{4}$ there is the possibility of an annual revision of prices set by the Ministry of Economy through the procedure of international comparison. The revision is not applied whenever the price variation is below 2.5\%. In late 2005 and beginning of 2006 , the Government has imposed a $6 \%$ decrease (each year) in the prices of pharmaceutical products. A more detailed description of each measure is presented below.

We assess the impact of this stream of policy measures on aggregate pharmaceutical spending, using a time-series approach to endogenously detect structural breaks. Then, confronting the time of the break with the timetable of policy measures we identify which measures may be at the root of observed changes (if any). Our approach is similar, in a broad sense, to the works of Ong et al (2003) and Clemente et al (2007). Ong et al (2003) address the impact of an increase in copayments on the consumption of antidepressants, anxiolytics and sedatives in Sweden (during the nineties). Using the notions of spikes (one-shot changes), decays (a spike which vanishes gradually) and steps (permanent shifts they look for evidence of each sort of impact after changes in copayment levels. They find no impact from copayments raises in 1995 and 1997 but for a women's use reduction if antidepressants following the 1997 change Clemente et al. (2007) is the most recent example of aggregate, cross-country, panel data analysis related to pharmaceutical spending (for the earlier literature, see the references therein).

\footnotetext{
${ }^{4}$ Portaria $300-\mathrm{A} / 2007$ of 19 March.
} 
One of the challenges resulting from their analysis is the need for a more detailed knowledge at the level of each country. We present here the contribution from a small European country, with a relatively high level of copayment in pharmaceutical consumption and a high frequency of policy measures. The absence of a large domestic base in innovation expenditures associated with new pharmaceutical products also means that the main focus of policy intervention is the level and growth of pharmaceutical expenditures, and not promoting R\&D of domestic firms. ${ }^{5}$

\section{Data}

The three main series are the payments made by the NHS (enc), the total sales in value of pharmaceutical products ( $p v p)$ and the number of boxes sold $(e m b)$, taken as a crude proxy to the notion of quantity, relative to the NHS-reimbursed drugs. In addition, we have also used overall market data on sales in both value and number of boxes sold (the overall market includes both over-the-counter and NHS-reimbursed pharmaceutical products). All the data was compiled from public sources and checked with Infarmed, the Portuguese regulatory authority for pharmaceutical products. The value series (enc and $p v p$ ) were deflated by the CPI $(2002=100)$, to measure the value in terms of prices of a composite good made up of all the economy's production. By NHS market we refer to the pharmaceutical products that have a fraction of the respective price paid by the NHS. In what follows, we will also use the series in logs (denoted as LENC, $L E M B$ and $L P V P)$.

From Figure 3, we can observe that all three series have a very similar behaviour over time. The common evolution becomes even clearer when we look at the joint graph of the normalized series in Figure 4.

\footnotetext{
${ }^{5}$ There are very few Portuguese-based pharmaceutical firms conducting R\&D. The year 2009 will see the result of their effort with the first international launch of a new, patented, drug.
} 
Figure 3.
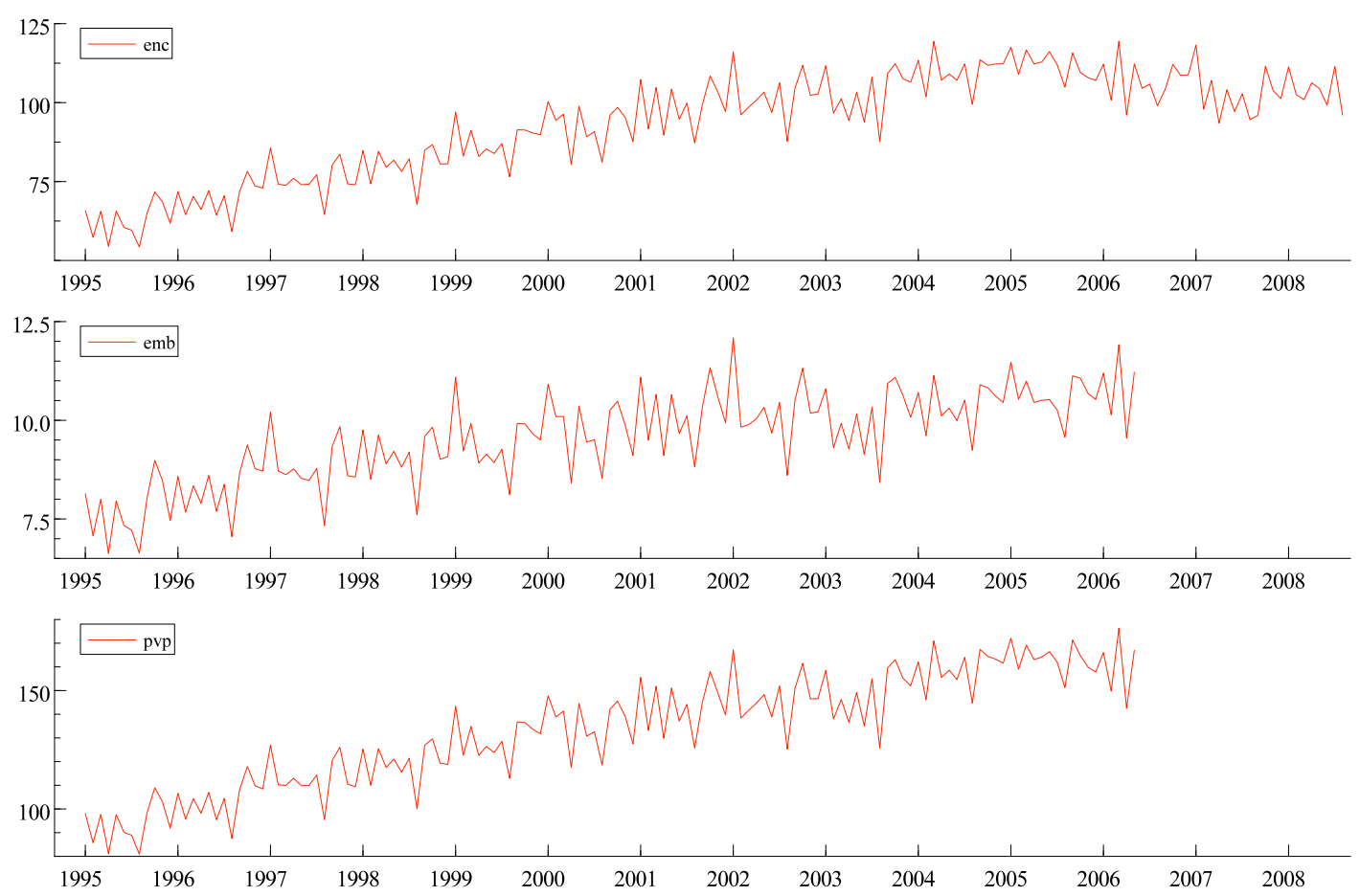

All the three series seem to share a similar pattern, with a steady growth up to 2005 , and a flattening, or even decrease, in the latter part of the period. The year 2003 also appears to have been somewhat special. This suggests the usefulness of testing for the presence of eventual structural breaks, which then we try to link to the timing of policy measures adopted. 


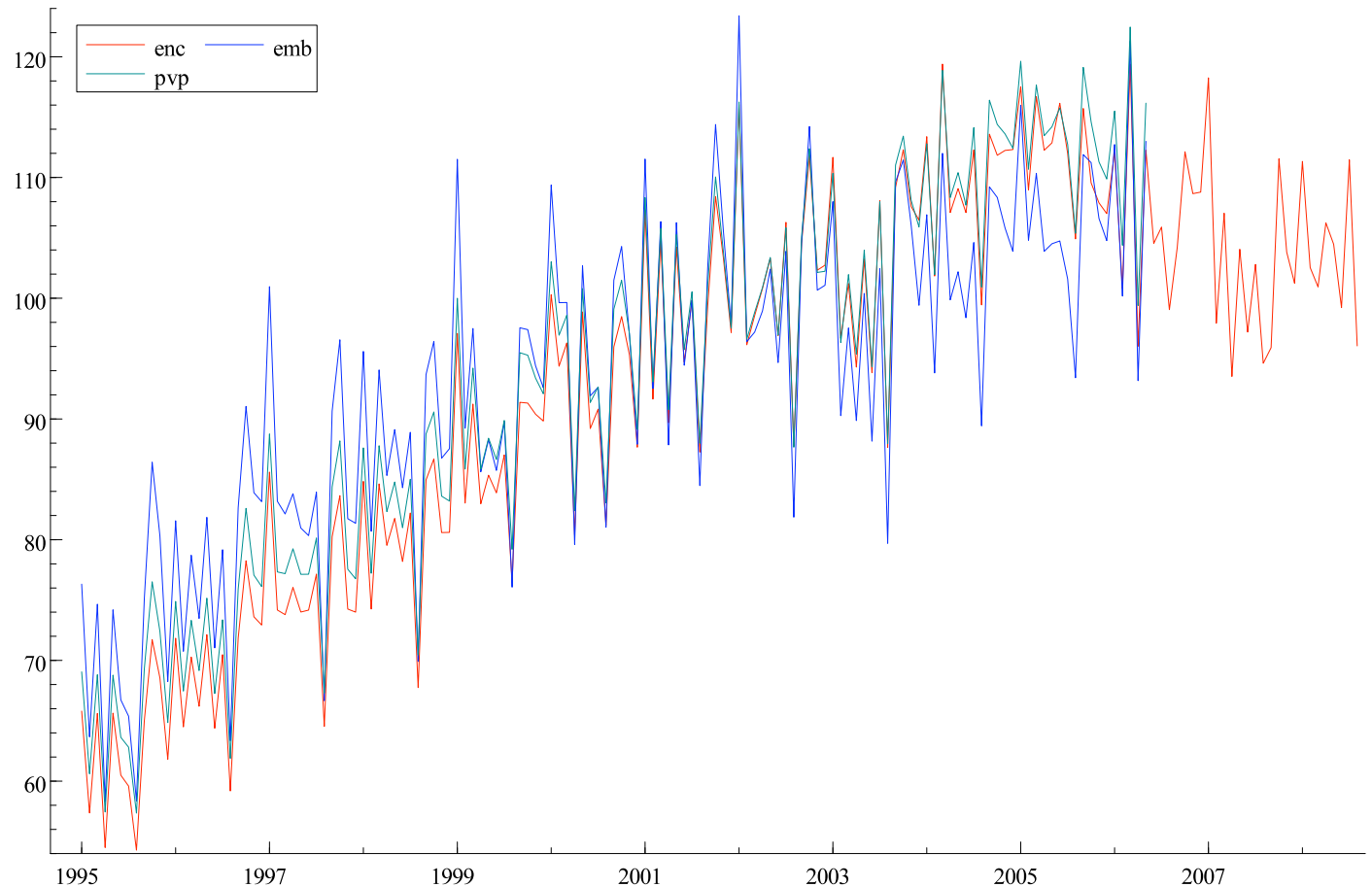

\section{Structural Time Series Modelling}

In our analysis we adopt a structural time series approach as it provides a consistent framework to identify the different impacts of interventions in time series characterized by trends, seasonalities and potential non-stationary behaviours. This approach has several advantages when compared to others methods such as the ARIMA models. The major components of a time series, such as the trend or the seasonal components can be explicitly modelled and estimated. Also, the adopted model is general enough to allow for different types of non-stationarity. Finally, the extension to a multivariate framework is quite straightforward.

The adopted statistical model allows one to decompose a time series into several unobserved components. The model is known as the Basic Structural Model (see Harvey, 1989) and considers a local linear trend with stochastic seasonality plus noise:

$$
\mathrm{y}_{\mathrm{t}}=\mu_{\mathrm{t}}+\mathrm{s}_{\mathrm{t}}+\varepsilon_{\mathrm{t}}, \varepsilon_{\mathrm{t}} \sim \mathrm{NID}\left(0, \sigma_{\varepsilon}^{2}\right)
$$

where $\mu_{\mathrm{t}}$ denotes the trend, $\mathrm{s}_{\mathrm{t}}$ the seasonal component, and $\varepsilon_{\mathrm{t}}$ the irregular component. The trend component is stochastic and specified as:

$$
\mu_{\mathrm{t}}=\mu_{\mathrm{t}-1}+\beta_{\mathrm{t}-1}+\eta_{\mathrm{t}}, \eta_{\mathrm{t}} \sim \mathrm{NID}\left(0, \sigma_{\eta}{ }^{2}\right),
$$




$$
\beta_{\mathrm{t}}=\beta_{\mathrm{t}-1}+\zeta_{\mathrm{t}}, \quad \zeta_{\mathrm{t}} \sim \mathrm{NID}\left(0, \sigma_{\zeta}^{2}\right)
$$

where $\beta_{\mathrm{t}}$ is the (stochastic) slope of the trend $\mu_{\mathrm{t}}$. The irregular component, $\varepsilon_{\mathrm{t}}$, and the shocks to the level, $\eta_{\mathrm{t}}$, and to the slope, $\zeta_{\mathrm{t}}$, are uncorrelated. The special case of a deterministic linear trend plus noise model is obtained when $\sigma_{\eta}{ }^{2}=\sigma_{\zeta}^{2}=0$. When these two variances are positive, both the trend level and slope are allowed to vary over time. For the seasonal component $s_{t}$ we adopt a trigonometric specification allowing for a smooth seasonal process using a flexible parameterization given by

$$
\mathrm{s}_{\mathrm{t}}=\mathrm{s}_{1 \mathrm{t}}+\ldots+\mathrm{s}_{6 \mathrm{t}},
$$

where

$$
\left(\begin{array}{c}
s_{j, t+1} \\
s_{j, t+1}^{*}
\end{array}\right)=\left[\begin{array}{cc}
\cos \lambda_{j} & \sin \lambda_{j} \\
-\sin \lambda_{j} & \cos \lambda_{j}
\end{array}\right]\left(\begin{array}{c}
s_{j, t} \\
s_{j, t}^{*}
\end{array}\right)+\left(\begin{array}{c}
\omega_{j, t+1} \\
\omega_{j, t+1}^{*}
\end{array}\right),
$$

with frequency $\lambda_{j}=\pi j / 6$, for $j=1, \ldots, 6$. The disturbances are assumed i.i.d. with a normal distribution with mean zero and identical variances $\sigma_{\omega}^{2}$. The parameters of this model are estimated by maximum likelihood by resorting to a state-space formulation and using the Kalman filter to estimate the unobserved components.

The effects of interventions or structural changes due to the introduction of new policy measures or to changes in regulations are easily introduced in this model by adding extra intervention, or dummy, variables to the model:

$$
\mathrm{y}_{\mathrm{t}}=\mu_{t}+s_{t}+\sum_{i=1}^{K} \alpha^{i} I_{t}^{i}+\varepsilon_{t}
$$

where the intervention variables $I_{t}^{i}, i=1, \ldots, K$, capture different types of intervention effects. We consider three different types. The first case considered corresponds to an outlying observation, or outlier, due to the transitory and isolated effect of an intervention that has an impact in a single period only. In this case, the variable $I_{t}^{i}$ is defined as a dummy variable that takes the value 1 in that period and the value 0 in all other periods. Another type of structural change is called a level change and corresponds to a shift in the level of the series occurring at some point in time and can be captured by defining the variable $I_{t}^{i}$ equal to 0 before that period, and equal to 1 afterwards. This type of structural change can be interpreted as a transitory shock that affects the level but has no effect on the slope of the trend. Finally, a permanent change in the slope can be captured in our model by defining $I_{t}^{i}$ as equal to 0 before the break date, which we denote as $\tau^{\mathrm{i}}$, and equal to (t$\tau^{\mathrm{i}}$ ) afterwards. Note that it is possible for a given intervention to result in several of these effects leading to more than one intervention variable defined for the same break date being included in 
the model. An example is a measure that simultaneously decreases the level and the slope of a series at some point in time whose effect is captured by including both a level and a slope change intervention variable in the model.

In our study, the number, type and location of the structural changes are determined endogenously, that is, they are estimated from the data itself. This is done in the following sequential manner. First, the basic structural model without intervention variables as in equation (1) is estimated. As shown in Harvey and Koopman (1992), it is possible to use the auxiliary residuals to identify the location and type of structural changes. The model in equation (2) is then estimated including all the $\mathrm{K}$ intervention variables that were identified. Finally, only those intervention variables that are significant in this re-estimated model are kept in the final model. ${ }^{6}$

The previous model was described in a univariate setting. It is straightforward to extend it to a multivariate setting and to identify and estimate the time series components and intervention variables for a vector of time series variables (for details see Harvey, 1989, and Koopman et al, 2007). In terms of estimated parameters, in a multivariate setting, it is necessary to consider not only the variances of each component's disturbance term but the covariances/correlations matrices for each component vector. As in the univariate case, in this model it is also assumed that the level, slope, seasonal and irregular disturbances are independent.

\section{Estimation Results}

The Basic Structural Model allowing for structural changes defined in equation (2) was applied to each individual series. The estimation results appear in Table 1. The estimated standard deviations of the disturbances associated with each of the components suggest that the variability of the slope shocks $\zeta_{t}$ is relatively small implying that the slope components $\beta_{t}$ will show little variation across time. This is confirmed by the graph of the estimated slope components appearing in Figures 5-7 for each of the variables considered.

Table 1 also presents the estimated structural changes for each variable. There is a single outlier detected in April 2004 for the LPVP series. However, there is evidence of the existence of some level shifts. Both the LENC and LPVP present a negative level shift in October 2005. For the LENC series, there is also evidence of a second level shift occurring in February 2007. The LEMB series presents a single level shift in January 2003. None of the series presented any evidence of a structural change in the slope. Therefore, although all detected level shifts had a negative coefficient, the associated decreases in the level were of a temporary nature due to the fact that the trend slope has remained relatively stable and positive throughout the entire sample

\footnotetext{
${ }^{6}$ All computations were done in STAMP 8 (see Koopman et al., 2007).
} 
period. This aspect is also clear in Figures 5-7 by observing the plot of the sum of the level and the intervention components, $\mu_{t}+\sum_{i=1}^{K} \alpha^{i} I_{t}^{i}$, over time.

The estimation results for the multivariate model are presented in Table 2. The high comovement in the three series is reflected in the estimated correlations of the components across the series being very close to 1 . As in the univariate case, the variable of the slope disturbances is relatively small.

The detected structural changes are also similar to the ones found in the univariate analysis. The early 2003 level shift is now detected for all the three series. For the LENC and the LPVP series, the 2005 level shifts are detected again although one month earlier. For the LEMB, a new level shift is detected in December 2003. The 2007 level shift in the LENC series is not detected because of the smaller sample size of the LEMB and LPVP series. As before, there is no evidence of any structural change in the trend slopes of our series.

Table 1. Estimation results for the univariate models

\begin{tabular}{|c|c|c|c|}
\hline & LENC & LEMB & LPVP \\
\hline \multicolumn{4}{|c|}{ Components Standard Deviations } \\
\hline Level $\left(\sigma_{\eta}\right)$ & 0.0050 & 0.0022 & 0.0051 \\
\hline Slope $\left(\sigma_{\zeta}\right)$ & 0.0003 & 0.0004 & 0.0004 \\
\hline Seasonal $\left(\sigma_{\omega}\right)$ & 0.0015 & 0.0000 & 0.0005 \\
\hline $\operatorname{Irregular}\left(\sigma_{\varepsilon}\right)$ & 0.0307 & 0.0352 & 0.0325 \\
\hline \multicolumn{4}{|l|}{ Outliers } \\
\hline Date & & & 2000:04 \\
\hline Coefficient & & & -0.100 \\
\hline (t-value) & & & $(-2.78)$ \\
\hline \multicolumn{4}{|l|}{ Level Shifts } \\
\hline Date & $2005: 10$ & 2003:01 & $2005: 10$ \\
\hline Coefficient & -0.102 & -0.061 & -0.086 \\
\hline (t-value) & $(-4.61)$ & $(-2.99)$ & $(-3.49)$ \\
\hline Date & 2007:2 & & \\
\hline Coefficient & -0.090 & & \\
\hline (t-value) & $(-3.88)$ & & \\
\hline Log-likelihood & 454.562 & 373.001 & 373.694 \\
\hline No. Observations & 164 & 137 & 137 \\
\hline $\mathrm{R}_{\mathrm{s}}^{2}$ & 0.516 & 0.541 & 0.539 \\
\hline
\end{tabular}

Note: t-statistics appear in parenthesis. 
Figure 5. Estimated level+interventions $\left(\mu_{t}+\sum_{i=1}^{K} \alpha^{i} I_{t}^{i}\right)$ and slope $\left(\mathrm{s}_{\mathrm{t}}\right)$ components for enc
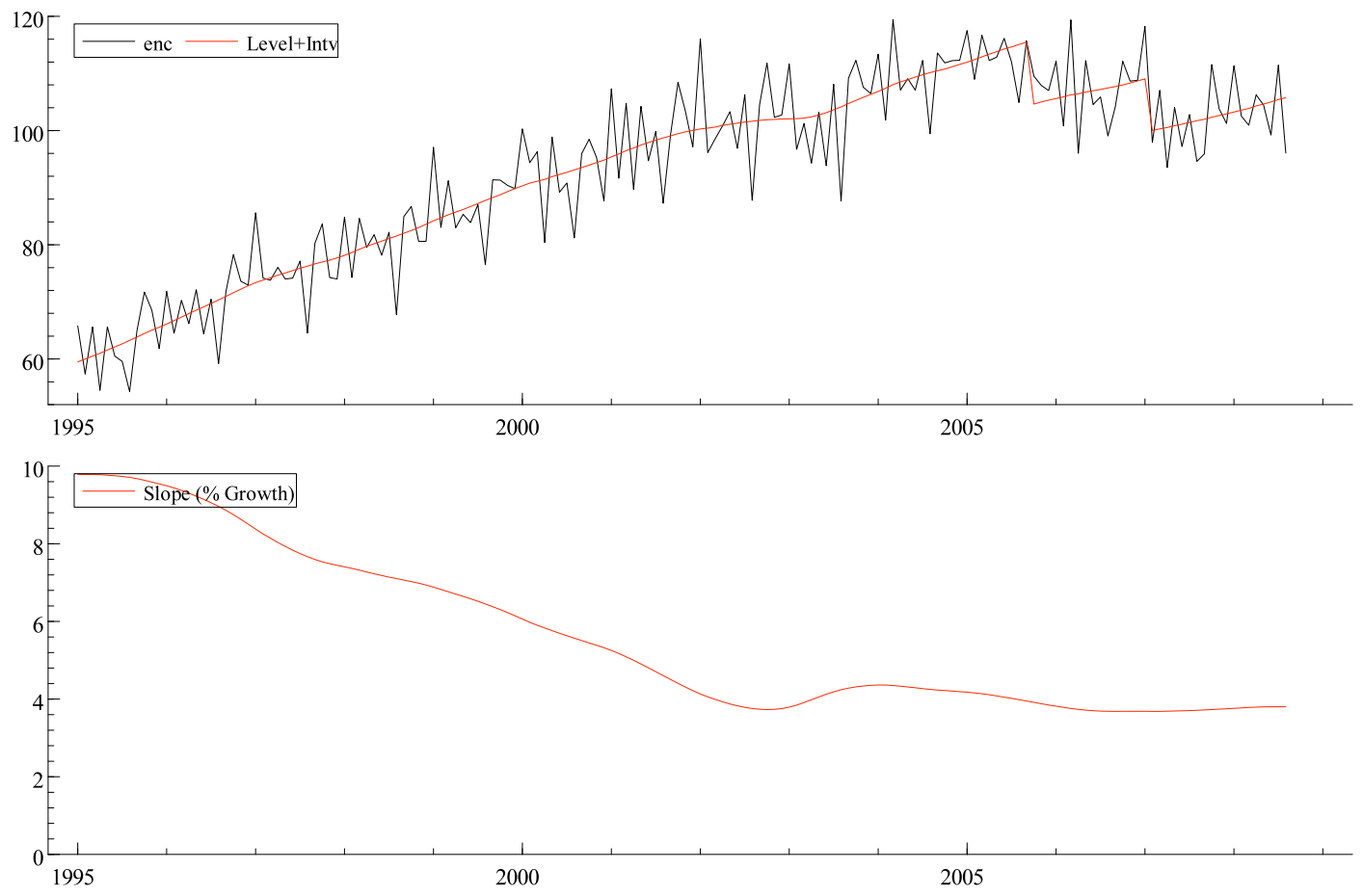

Figure 6. Estimated level+interventions $\left(\mu_{t}+\sum_{i=1}^{K} \alpha^{i} I_{t}^{i}\right)$ and slope $\left(\mathrm{s}_{\mathrm{t}}\right)$ components for $e m b$
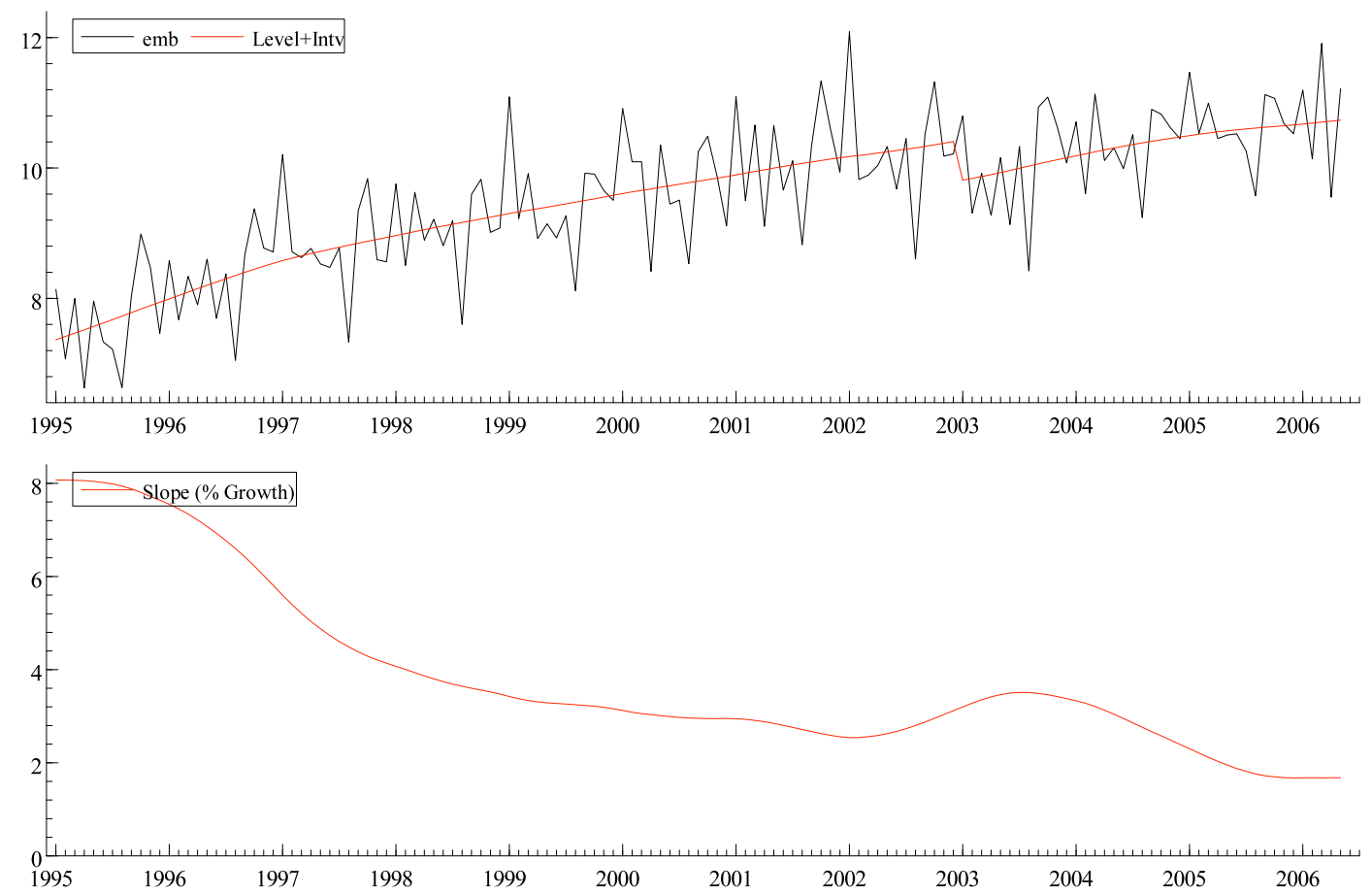
Figure 7. Estimated level+interventions $\left(\mu_{t}+\sum_{i=1}^{K} \alpha^{i} I_{t}^{i}\right)$ and slope $\left(\mathrm{s}_{\mathrm{t}}\right)$ components for pvp
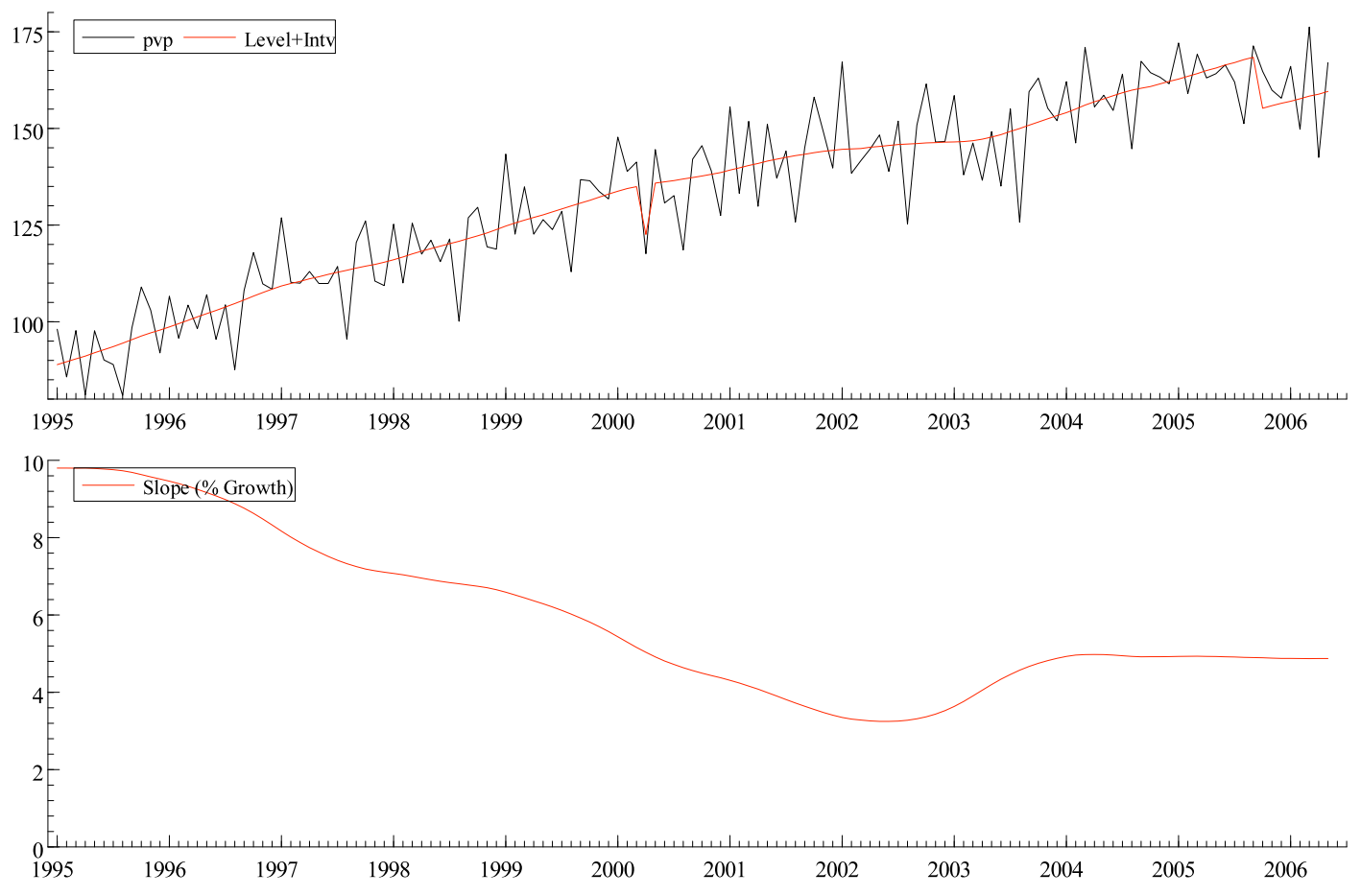
Table 2. Estimation results for multivariate model

\begin{tabular}{|c|c|c|c|}
\hline & LENC & LEMB & LPVP \\
\hline \multicolumn{4}{|c|}{ Components Standard Deviations } \\
\hline Level $\left(\sigma_{\eta}\right)$ & 0.0044 & 0.0064 & 0.0015 \\
\hline Slope $\left(\sigma_{\zeta}\right)$ & 0.0005 & 0.0000 & 0.0000 \\
\hline Seasonal $\left(\sigma_{\omega}\right)$ & 0.0012 & 0.0000 & 0.0001 \\
\hline $\operatorname{Irregular}\left(\sigma_{\varepsilon}\right)$ & 0.0322 & 0.0046 & 0.0000 \\
\hline \multicolumn{4}{|l|}{ Correlation Matrices } \\
\hline \multirow[t]{2}{*}{ Level } & LENC & 0.651 & 0.940 \\
\hline & LEMB & - & 0.762 \\
\hline \multirow[t]{2}{*}{ Slope } & LENC & 1 & 1 \\
\hline & LEMB & - & 1 \\
\hline \multirow[t]{2}{*}{ Seasonal } & LENC & 1 & 0,996 \\
\hline & LEMB & - & 0,996 \\
\hline \multirow[t]{2}{*}{ Irregular } & LENC & 0,990 & 0,999 \\
\hline & LEMB & - & 0,995 \\
\hline \multicolumn{4}{|l|}{ Outliers } \\
\hline Date & 2005:01 & & \\
\hline Coefficient & -0.007 & & \\
\hline (t-value) & $(-3.45)$ & & \\
\hline \multicolumn{4}{|l|}{ Level Shifts } \\
\hline Date & 2003:03 & 2003:01 & 2003:03 \\
\hline Coefficient & -0.034 & -0.023 & -0.019 \\
\hline (t-value) & $(-4.00)$ & $(-3.55)$ & $(-2.68)$ \\
\hline Date & 2005:09 & 2003:12 & 2005:09 \\
\hline Coefficient & -0.045 & -0.026 & -0.025 \\
\hline (t-value) & $(-4.90)$ & $(-4.11)$ & $(-3.29)$ \\
\hline Log-likelihood & & 1621.05 & \\
\hline No. Observations & & 137 & \\
\hline $\mathrm{R}_{\mathrm{s}}^{2}$ & 0.547 & 0.538 & 0.539 \\
\hline
\end{tabular}




\subsection{Discussion}

Having the information on the structural breaks dictated by the data, we confront the results with the key policy measures taken during this period. In the previous section we identified the existence of structural breaks in October 2005 and February 2007 for the series of Government outlays with reimbursement of population costs with pharmaceutical products. The breaks were more visible in the series of Government expenditures with reimbursement of listed pharmaceutical products. In particular, the 2007 break does not appear in any of the two other series, while the 2005 break also shows up in the total sales value series but not on the number of boxes sold series. When all series are taken together, the 2007 break can no longer be identified. Instead, an earlier break, in the first quarter of 2003 is detected. The common characteristic is the absence of trend changes. All structural breaks are characterized by one-time decreases in expenditure, with underlying economic forces, which drive the dynamics of pharmaceutical expenditure, being unchanged. The main measures adopted in the period covered by the series are described in Table 3.

Table 3. Main policy measures

\begin{tabular}{|c|c|c|}
\hline Date & $\begin{array}{l}\text { Legal } \\
\text { document }\end{array}$ & Content \\
\hline $\begin{array}{l}7^{\text {th }} \text { October, } \\
1998\end{array}$ & $\begin{array}{l}\text { Law-Decree } \\
305 / 98\end{array}$ & $\begin{array}{l}\text { Changes in the copayment regime. It imposes the need for an economic } \\
\text { evaluation study for drugs to be listed for NHS reimbursement. }\end{array}$ \\
\hline $\begin{array}{l}1^{\text {st }} \text { September, } \\
2000\end{array}$ & $\begin{array}{l}\text { Law-Decree } \\
205 / 00\end{array}$ & $\begin{array}{l}\text { Changes in the copayment regime, giving } 10 \% \text { more in the } \\
\text { reimbursement rate to generics. }\end{array}$ \\
\hline $\begin{array}{l}5^{\text {th }} \text { September, } \\
2000\end{array}$ & $\begin{array}{l}\text { Portaria } \\
79 / 2000\end{array}$ & $\begin{array}{l}\text { Price changes: new pharmaceutical products must be at least } 5 \% \text { cheaper } \\
\text { than existing alternatives in the market. Rules for delisting are also } \\
\text { established. }\end{array}$ \\
\hline $7^{\text {th }}$ June, 2001 & $\begin{array}{l}\text { Portaria } \\
577 / 201\end{array}$ & $\begin{array}{l}\text { Price changes, namely the rules for generic drugs' prices (generics' } \\
\text { prices must be at least } 35 \% \text { below the price of the branded drug). }\end{array}$ \\
\hline $\begin{array}{l}5^{\text {th }} \text { December, } \\
2002\end{array}$ & $\begin{array}{l}\text { Portaria } \\
1492- \\
\text { A/2002 }\end{array}$ & $\begin{array}{l}\text { Establishes changes of pharmaceutical prices, with increases in most } \\
\text { cases between } 1.5 \% \text { (products with prices in the range } 5-10 € \text { ) and } 5 \% \\
\text { (products with prices below } 5 € \text { ). }\end{array}$ \\
\hline $\begin{array}{l}2^{\text {nd }} \text { December, } \\
2002\end{array}$ & $\begin{array}{l}\text { Law-Decree } \\
270 / 02\end{array}$ & $\begin{array}{l}\text { It creates the reference pricing system, reinforcing the role of generic } \\
\text { drugs. The reference price in each homogeneous group of } \\
\text { pharmaceutical products is determined by the highest generic price). } \\
\text { Further legislation connected to this piece below. The system became } \\
\text { effective in March } 2003 \text {. }\end{array}$ \\
\hline $\begin{array}{l}27^{\text {th }} \text { September, } \\
2003\end{array}$ & $\begin{array}{l}\text { Law-Decree } \\
234 / 03\end{array}$ & $\begin{array}{l}\text { Extends the application of the Decree-Law } 270 / 2002 \text { (use of the } \\
\text { reference pricing system) to public health subsystems. }\end{array}$ \\
\hline $\begin{array}{l}1^{\text {st }} \text { December, } \\
2003\end{array}$ & $\begin{array}{l}\text { Portaria } \\
914 / 2003\end{array}$ & $\begin{array}{l}\text { Establishes changes in price setting for generic drugs (imposing that new } \\
\text { generic products cannot enter with a price above the reference price). }\end{array}$ \\
\hline $\begin{array}{l}6^{\text {th }} \text { February, } \\
2004\end{array}$ & $\begin{array}{l}\text { Law-Decree } \\
31 / 04\end{array}$ & $\begin{array}{l}\text { Extends for one more year an extra co-insurance rate of } 25 \% \text { for generic } \\
\text { drugs bought by elderly people. }\end{array}$ \\
\hline $\begin{array}{l}21^{\text {st }} \text { December, } \\
2004\end{array}$ & $\begin{array}{l}\text { Portaria } \\
1471 / 2004\end{array}$ & $\begin{array}{l}\text { It establishes the rules to be followed in the definition of boxes of } \\
\text { pharmaceutical products that have a share of their price reimbursed by } \\
\text { the Government. }\end{array}$ \\
\hline $\begin{array}{l}21^{\text {st }} \text { December, } \\
2004\end{array}$ & $\begin{array}{l}\text { Portaria } \\
1474 / 2004\end{array}$ & $\begin{array}{l}\text { Redefines the groups of pharmaceutical products, following the adoption } \\
\text { of a new pharmacotherapeutic classification. Does not change the set of } \\
\text { products covered by the NHS. }\end{array}$ \\
\hline
\end{tabular}




\begin{tabular}{|c|c|c|}
\hline $27^{\text {th }}$ June, 2005 & $\begin{array}{l}\text { Portaria } \\
618-\mathrm{A} / 2005\end{array}$ & $\begin{array}{l}\text { It sets an administrative price reduction of } 6 \% \text { in all pharmaceutical } \\
\text { products. Complemented with Portaria } 826 / 2005 \text { of } 14 \text { September, } \\
\text { about sales of existing stocks at previous prices (until } 31.10 .2005 \text { ). } \\
\text { Effective } 15.10 .2005 \text {. It opens an exception for products of companies } \\
\text { investing more than } 5 \mathrm{M} € \text { in R\&D in Portugal. It reduces margins for } \\
\text { wholesale and retail distribution. }\end{array}$ \\
\hline $\begin{array}{l}\text { 11th August, } \\
2005\end{array}$ & $\begin{array}{l}\text { Law-Decree } \\
129 / 05\end{array}$ & $\begin{array}{l}\text { Changes again the reimbursement system: reduces in } 5 \% \text { the highest co- } \\
\text { insurance rate of the NHS coverage of pharmaceutical products. } \\
\text { Eliminates the extra coverage rate associated with generic products. It } \\
\text { provides additional reimbursement coverage for the poor elderly } \\
\text { (defined as those with pensions below the minimum wage). }\end{array}$ \\
\hline $\begin{array}{l}\text { 10th February, } \\
2006\end{array}$ & $\begin{array}{l}\text { Protocol } \\
n^{\circ} 7 / 2006\end{array}$ & $\begin{array}{l}\text { Agreement between the pharmaceutical industry and the Government to } \\
\text { set a ceiling for the growth of public spending with pharmaceutical } \\
\text { products. If the growth of public pharmaceutical expenditure exceeds a } \\
\text { limit, then a fraction of that excess is paid back by the industry. }\end{array}$ \\
\hline $4^{\text {th }}$ July, 2006 & $\begin{array}{l}\text { Decree-Law } \\
127 / 06\end{array}$ & $\begin{array}{l}\text { Reduces from } 30 \% \text { to } 20 \% \text { the extra co-insurance rate given to generic } \\
\text { drugs acquired by NHS patients included in the special regime (poor and } \\
\text { pensioners). }\end{array}$ \\
\hline $\begin{array}{l}5^{\text {th }} \text { January, } \\
2007\end{array}$ & $\begin{array}{l}\text { Portaria 30- } \\
\text { B/2007 }\end{array}$ & $\begin{array}{l}\text { Reduces the price of all pharmaceutical products included in the NHS } \\
\text { coverage by } 6 \% \text {. It reduces wholesale and retail margins. Effective } \\
31.01 .2007 \text {. }\end{array}$ \\
\hline $\begin{array}{l}14^{\text {th }} \text { March, } \\
2007\end{array}$ & $\begin{array}{l}\text { Decree-Law } \\
65 / 07\end{array}$ & $\begin{array}{l}\text { Imposes a mandatory price reduction in prices of generic drugs } \\
\text { whenever their market share gets above a certain threshold. Changes the } \\
\text { international referencing procedure for pricing of new drugs. }\end{array}$ \\
\hline $\begin{array}{l}\text { 19th March, } \\
2007\end{array}$ & $\begin{array}{l}\text { Portaria } \\
300-\mathrm{A} / 2007\end{array}$ & $\begin{array}{l}\text { It establishes the possibility of pharmacies giving price discounts on the } \\
\text { pharmaceutical products they sell (making prices set by the Government } \\
\text { maximum prices instead of fixed prices) and details reductions generic } \\
\text { prices according to market share (as set by the general principle laid } \\
\text { down in Decree-Law } 65 / 07 \text { ). }\end{array}$ \\
\hline
\end{tabular}

From 1995 to 2001, we have seen a downward trend in the growth rate of pharmaceutical expenditure by the NHS, which has essentially levelled off after this date. This is quite clear after the exogenous price reductions associated with the structural breaks are reduced. This evidence supports the interpretation that even if total expenditure went down, the economic forces behind the growth of pharmaceutical expenditures have not been touched in a significant way. Therefore, the effect on spending even it noticeable will be temporary. The underlying sustained growth will take total spending levels to the previous levels in the short to medium run.

A temporary effect in early 2003 coincides with the start of the reference pricing system. The effective start of the reference pricing system in March 2003 seems therefore ot be associated with a decrease in sales values, resulting from price adjustments of branded drugs that face competition from generics under the newly introduced reference pricing system. The temporary effect is detected in all three series (total sales, number of boxes sold - with a lead of two periods - and expenditures by the NHS). For a period of 6 to 9 months, overall public expenditure growth was reduced. However, after this adaptation period, firms were able to resume their historical growth of sales and NHS payments were again aligned with historical growth. Basically, our

\footnotetext{
${ }^{7}$ It is now the average price of four reference countries (Spain, Italy, Greece and France).
} 
analysis detects only a level shift around 2003 in the series of sales values and NHS reimbursements. Since the underlying growth rate did not change (no break in slope), the historical trend resumed shortly after. Graphically, the temporary effect is clearly visible in a slowdown of pharmaceutical expenditures, followed by a slight acceleration that takes the series back to its historical path. The second break detected under the joint analysis of the three series (covering the period January 1995 to May 2006) occurs in September 2005, roughly coinciding with the first administratively determine price decrease in pharmaceutical products. Using the longer time series for reimbursement payments made by the NHS, running from January 1995 to July 2008, this last structural break is identified with October and the administrative price decrease of February 2007 also shows up as a structural break. The longer time series does not detect the (short-lived) initial impact of introduction of the reference pricing system in March $2003 .^{8}$

From the above description of the main policy measures in the pharmaceutical market, it becomes clear that only two policy measures were adopted in the months prior to the structural breaks found: the administrative price changes. It is also relevant to note that the change in box sizes, imposed to reduce waste and adjust box sizes to the therapeutic needs of patients, and the change in the pharmacologic groups did not have any impact on the market evolution. In addition, the series on boxes sold $(\mathrm{emb})$ does not show any noticeable structural break. We therefore need to look for other policy measures that either take a longer time to produce effects, or that have reinforced the initial impetus produced by the box-sizes law.

The introduction of the reference pricing system apparently had temporary impact on growth of pharmaceutical sales during 2003, which seems to have been countervailed by early 2004. However, the reference pricing system, with its regular price update and entry of new products, is still a candidate to explain the trend change.

During 2005, the more emblematic measure was the $6 \%$ administrative price reduction, adopted in June and effective in September 2005, a measure repeated in late 2006, effective in early 2007. These administrative price reductions had an important impact. However, a change in the price level of all pharmaceutical products should result in a reduction of payments by both the NHS and the patients. Since a trend reversal is identified in the overall sales series ( $p v p)$ in 2005 (but not in 2007), this remains a candidate to be the main driving force behind the structural

\footnotetext{
${ }^{8}$ We were not able to obtain longer time series for the number of boxes and total sales corresponding to the pharmaceutical products reimbursed by the NHS. Instead, more recent data only have information on both value and boxes total market sales (which includes pharmaceutical products not in the list the NHS) and NHS reimbursement payments. Using the same procedure on these three series, running from July 2003 to July 2008, no effect is detected, as randomness of the series seems to be too high for detection of structural breaks. Details are available from the authors upon request.
} 
break. It is actually interesting to note that pharmaceutical companies were able to sustain growth in sales at a pace broadly in line with the historic trend. Since no systematic change in the "quantity" measure (number of boxes sold) took place, the ability to keep sales growth is conjectured to be the result of a composition effect: a move in sales from relatively low-price drugs to high-priced ones after the 2007 administratively determined price decrease. The level of aggregation we have available in the data, we cannot probe further. This is an issue left for future research.

It is also apparent that such measures created only a level effect, as the underlying dynamics (growth rate) did not change in a substantive way, once we remove the discrete effect of the $6 \%$ price reduction across the board.

Importantly, the agreement with the pharmaceutical industry to contain public expenditure, signed in February 2006, may have created a general mood for marketing efforts of pharmaceutical companies favouring control of public expenditure growth, and does not seem to have helped to sustain it as a trend reversal.

Since the agreement focus solely on the public expenditure side, one may anticipate a reaction of pharmaceutical companies emphasizing their products with lower reimbursement from the NHS (as this would it make easier to be under the ceiling). Since other measures, adopted during this period, increased patients' share, we may have a first look at their role. The number of statistical observations is still too short to make proper tests. Nonetheless, Figure 8 is suggestive of the shift of costs from the NHS to patients', implying that the change was stronger in payments made by the NHS. ${ }^{9}$ The simple price reduction does not account for this phenomenon in a complete way. Unfortunately, we do not have recent data on the NHS market total sales to assess recent evolution.

\footnotetext{
${ }^{9}$ The ratio used, total NHS reimbursements of pharmaceutical products over total sales, does not distinguish changes in the share of NHS-covered products in total market and changes in the average reimbursement rate in NHS-covered pharmaceuticals. The size (total sales) of the NHS-covered pharmaceutical products is not publicly known for more recent years. For a couple of years, both pieces of information were available, and the evolution NHS reimbursements over total sales and over NHS-covered total sales was similar.
} 
Figure 8: Reimbursement in the NHS relative to total sales

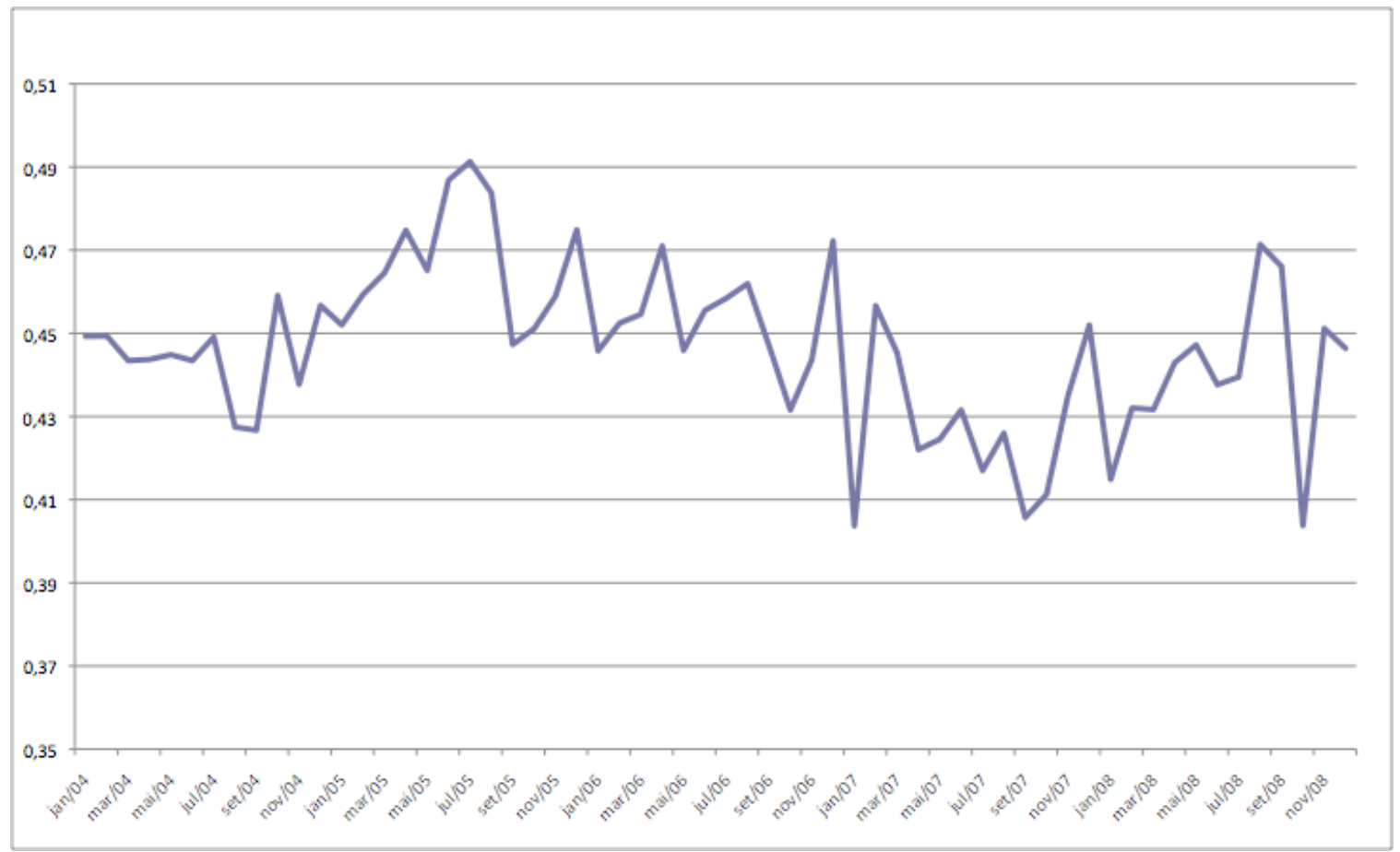

\section{Final remarks}

Many policy measures aimed at containing the expenditure with pharmaceutical products have been adopted in Portugal during the last ten years, similar to what was a general approach in many other countries. Using a time-series approach we let the data speak and identify endogenously breaks in the series of expenditure growth. The identified break points were then compared with the timetable of policy measures.

We can identify a transitory impact in the first half of 2003 coinciding with the start of the reference pricing system. However, the slowdown in the payments by the NHS on pharmaceutical products was relatively short lived. Before the end of the year, growth of pharmaceutical expenditure had returned to the historical path. The statistical model does not capture it as a structural break

The two structural breaks detected occur circa October 2005 and January 2007. The timing of the structural break does coincide with two measures in the prior months: the administratively determined price reductions in pharmaceutical products. However, Government determined price decreases have only a level effect. The underlying dynamics do not have changed. Accordingly, pharmaceutical companies were able to keep roughly historical growth trends, with measures resulting mainly in a shift of the financial burden from the NHS to patients. 
Our findings, based on the evolution of aggregate times series of pharmaceutical expenditure, do raise further questions, namely about the mechanisms by which firms adjust to policy measures. Taking again the discussion of Mossialos et al (2006), our results corroborate their view that creating competition from generics and an active role when defining reimbursement values for patented drugs is necessary for third-party payers to control pharmaceutical spending. Still, so far, there is no evidence of a sufficient policy tool, able to keep under control pharmaceutical spending. However, pharmaceutical companies' adjustment may make it just a mater of shifting financial burdens and not one of fundamental change in consumption patterns. Confirmation of this conjecture and identification of the demand factors and the instruments used by pharmaceutical companies that sustain consumption growth, despite the vast range of policy measures adopted, is beyond the scope of the paper and it is left for future research. 


\section{References}

Barros, P P and J A Simões, 2007, Portugal: Health System Review, Health Systems in Transition, 9(5): $1-150$.

Clemente, J, C Marcuello and A Montanes, 2007, Pharmaceutical expenditure, total health-care expenditure and GDP, Health Economics, forthcoming.

Danzon, P, R Wary and L Wang, 2005, The impact of price regulation on the launch delay of new drugs - evidence from twenty-five markets in the 1990s, Health Economics, 14(3): 269 292.

Fattore, G. and C. Jommi, 2008, The last decade of Italian pharmaceutical policy: instability or consolidation?, Pharmacoeconomics, 26(1): 5 - 15.

Fiorio, C. and L. Siciliani, 2008, The demand for pharmaceuticals: evidence from Italy, mimeo.

Harvey, A.C., 1989, “Forecasting, Structural Time Series Models and the Kalman Filter", Cambridge: Cambridge University Press.

Harvey, A.C. and S.J. Koopman, 1992, Diagnostic Checking of Unobserved-Components Time Series Models, Journal of Business \& Economic Statistics, American Statistical Association 10(4): 377-89.

Koopman, S.J., A.C. Harvey, J.A. Doornik and N. Shephard, 2007, "STAMP 8: Structural Time Series Analyser, Modeller and Predictor", Timberlake Consultants Press.

Lee, Y.-C., M.-C. Yan, Y.-T. Huang, C.-H. Liu and S.-B. Chen, 2006, Impacts of costcontainment strategies on pharmaceutical expenditures of the National Health Insurance in Taiwan, 1996 - 2003, Pharmacoeconomics, 24(9): 891 - 902.

Maynard, A and K Bloom, 2004, Dilemmas in the regulation of the market for pharmaceuticals, Health Affairs, 22: $31-41$.

Mossialos, E., D. Brogan and T. Walley, 2006, Pharmaceutical pricing in Europe: weighing up the options, International Social Security Review, 59(3): 3 - 25.

Ong, M., R. Catalano and T. Hartig, 2003, A time-series analysis of increased copayments on the prescription of antidepressants, anxiolytics, and sedatives in Sweden from 1990 to 1999.

Sisto, A. and Zanola, R., "The Determinants of Public Pharmaceutical Expenditures: Does Italian Health Federalism Impact on Them?" (November 2005). Available at SSRN: http://ssrn.com/abstract $=869762$

Street, A., A. Jones and A. Furuta, 1999, Cost-sharing and pharmaceutical expenditure in Russia, Journal of Health Economics, 18(4): $459-472$. 